\title{
Orthostatic tremor: current challenges and future prospects
}

This article was published in the following Dove Press journal:

Degenerative Neurological and Neuromuscular Disease

6 April 2016

Number of times this article has been viewed

\author{
Philip Babatunde Adebayo \\ Neurology Unit, Department of \\ Medicine, Faculty of Clinical Sciences, \\ Ladoke Akintola University of \\ Technology, Ogbomoșo, Oyo State, \\ Nigeria
}

\begin{abstract}
This review provides an outlook of orthostatic tremor (OT), a rare adult-onset tremor characterized by subjective unsteadiness during standing that is relieved by sitting or walking. Recent case series with a long-time follow-up have shown that the disease is slowly progressive, spatially spreads to the upper limbs, and other neurological disorders may develop in about onethird of the patients. The diagnosis of OT hinges on the typical history of unsteadiness during standing, which is confirmed by electromyographic findings of a $13-18 \mathrm{~Hz}$ tremor that is typically absent during tonic activation while the patient is sitting and lying. Although the tremor is generated by a central oscillator, cerebellar and/or basal ganglia dysfunction are needed for its manifestation (double lesion hypothesis). However, functional neuroimaging findings have not consistently implicated the dopaminergic system in its pathogenesis. Drug treatments have been largely disappointing with no sustained benefits, although thalamic deep brain stimulation has helped some patients. Large-scale follow-up studies, more drug trials, and novel therapies are urgently needed.
\end{abstract}

Keywords: orthostasis tremor, challenges, prospects, therapies, clinical course, drug trials

\section{Introduction}

Orthostatic tremor (OT) is a rare form of tremor and is characterized by subjective unsteadiness during standing, which is relieved by sitting or walking. Although Pazzaglia et al $^{1}$ reported it first, it was Heilman² in 1984 who brought the entity to limelight when he described the quivering movements of the legs and trunk during standing, often accompanied by a curious sensation of unsteadiness that was relieved by walking or leaning against an object often described as a tremor of the lower limbs and the trunk, extant evidence however shows that this tremor could involve other parts of the body, especially the upper extremities when they are used to maintain body weight or when they contract isometrically. ${ }^{3}$ The term Primary Orthostatic Tremor (POT) or idiopathic OT is used when the tremor (whether or not there is upper limb involvement) is not accompanied by additional neurological features. ${ }^{4}$ Recently, Ganos et $\mathrm{al}^{5}$ have used the term "isolated OT" as a nomenclature for POT; with or without upper extremities involvement. The term orthostatic tremor plus ("OT Plus") is used when OT is accompanied by other neurological symptoms or conditions. ${ }^{4}$ The term "Shaky Leg Syndrome" has been suggested by some other authors based on the fact that the tremor is not exclusively orthostatic and that it can also be induced by strong tonic contraction of the leg muscles. The latter terminology fails to reflect the possible involvement of other regions of the body such as the trunk or the upper extremities. ${ }^{6,7}$ The 
findings of Boroojerdi et $\mathrm{al}^{8}$ show that while OT is invariably present during stance or other weight-bearing positions, it is, however, not always associated with orthostasis. The term "Orthostasis-independent action tremor" has been suggested for this group of patients.

\section{Clinical presentation and diagnosis}

Classically, the clinical presentation is that of unsteadiness and fear of falling upon standing that has a latency of some seconds or infrequently a few minutes depending on the severity of the disease. ${ }^{4}$ The unsteadiness increases in intensity until the patient is forced to take a step or sit down to regain balance. When a patient with OT is examined during attempts to stand still, a fine rippling of the muscles of the legs is found. This rippling may be easier to feel than to $\operatorname{see}^{9,10}$ and sometimes, the tremor may be auscultated using a stethoscope. ${ }^{9}$ Typically; the diagnosis is reached when patients satisfy the clinical features as defined by the Consensus statement of the Movement Disorder Society on Tremor (Table 1). ${ }^{11}$

Neurophysiological recording using surface electromyography (EMG) confirms the presence of fast, $13-18 \mathrm{~Hz}$ bursts of muscle activities (Figure 1). Rhythmic activation of upper limbs muscles at the same frequency can be seen if the patient uses the upper limbs to maintain postures such as leaning on a walker or by standing on all fours or when the upper limbs muscles contract isometrically. ${ }^{12}$ Although high frequency is typical of OT, lower frequency OT characterized by $70-120 \mathrm{~ms}$ EMG bursts at frequencies $<12 \mathrm{~Hz}$ has been recognized. ${ }^{13,14}$ The occurrence of this low-frequency tremor

Table I Consensus statement on orthostatic tremor of the Movement Disorders Society

\begin{tabular}{ll}
\hline Diagnostic criteria for OT \\
\hline I & A subjective feeling of unsteadiness during stance but only \\
in severe cases during gait; patients rarely fall. None of the \\
patients have problems when sitting and lying \\
Sparse clinical findings that are mostly limited to a visible \\
and occasionally, only palpable fine amplitude rippling of the \\
leg (quadriceps or gastrocnemius) muscles when standing \\
The diagnosis that can be confirmed only by EMG \\
recordings (for example, from the quadriceps muscle) with \\
a typical I3-I8 Hz pattern. All of the leg, trunk, and even \\
arm muscles can show this tremor, which is typically absent \\
during tonic activation while the patient is sitting and lying \\
The diagnosis critically depends on electromyographic \\
confirmation of the high-frequency EMG pattern because \\
other tremors or symptoms (for example, akathisia, \\
cerebellar stance tremor) during stance can occur with \\
similar complaints
\end{tabular}

Note: Data from Deuschl et al."

Abbreviations: OT, orthostatic tremor; EMG, electromyography. with orthostasis have occasioned the division of OT into fast OT and slow OT. ${ }^{14,15}$ Although about a third of patients with OT have underlying disease, it appears that slow OT is often associated with other conditions and may have greater gait involvement and higher likelihood of falls leading to earlier presentation. ${ }^{15}$ Williams et $\mathrm{al}^{16}$ recently described a patient with cerebellar atrophy and a slow OT (frequency of $9 \mathrm{~Hz}$ ), while Baker et $\mathrm{al}^{17}$ reported a patient with multiple sclerosis and slow OT (frequency of $4 \mathrm{~Hz}$ ). Slow OT has also been reported in patients with Parkinson's disease (PD). ${ }^{18}$ Coffeng et $\mathrm{al}^{19}$ however reported a patient with slow OT (frequency $10-11 \mathrm{~Hz}$ ) without clinical or imaging evidence of underlying disease, providing proof of the existence of primary slow OT. Although Uncini et $\mathrm{al}^{13}$ had earlier reported a patient with slow OT without underlying disease, the description of the case was so minimal that a secondary origin of the tremor could not be assuredly excluded. ${ }^{19}$

\section{Descriptive demographic and clinical profile of OT patients}

Because of its rarity and absence of epidemiological data, incidence and prevalence studies are unknown. Few large case series (Table 2) are available in the literature; the largest is the recent series of Ganos et al. ${ }^{5}$ These case series have attempted to profile the demographic characteristics of patients with OT while endeavoring to describe the clinical picture and long-term outcome of the disease.

\section{Demography}

The mean age of onset in most studies is in the sixth decade of life while an obvious female preponderance (up to a ratio of four to one ${ }^{20}$ ) is reported by most authors except in the series of Yaltho and Ondo ${ }^{21}$ in which a slight male preponderance was found. When OT Plus syndrome in considered separately, the mean age of onset appears to vary between reports. Gerschlager et $\mathrm{al}^{22}$ found an average age of onset of 61.8 , while Yaltho and Ondo ${ }^{21}$ found a younger mean age of onset (55.9 years) in their cohort while Ganos et $\mathrm{al}^{5}$ found an average age of 58.3. This variation notwithstanding, there seems to be a trend toward the older age of onset for OT Plus.

Available studies reveal that most cases are sporadic, and a family history is rare. Among their cohorts of 45 and 68 patients, Yaltho and Ondo ${ }^{21}$ and Ganos et $\mathrm{al}^{5}$ found a positive family history of "Pure OT" in $7 \%$ and $1.6 \%$, respectively. A genetic linkage is however suggested by few reports of familial cases such as the reports of OT in monozygotic twins $^{23}$ and co-occurrence of OT and ET in two brothers. ${ }^{24}$ 


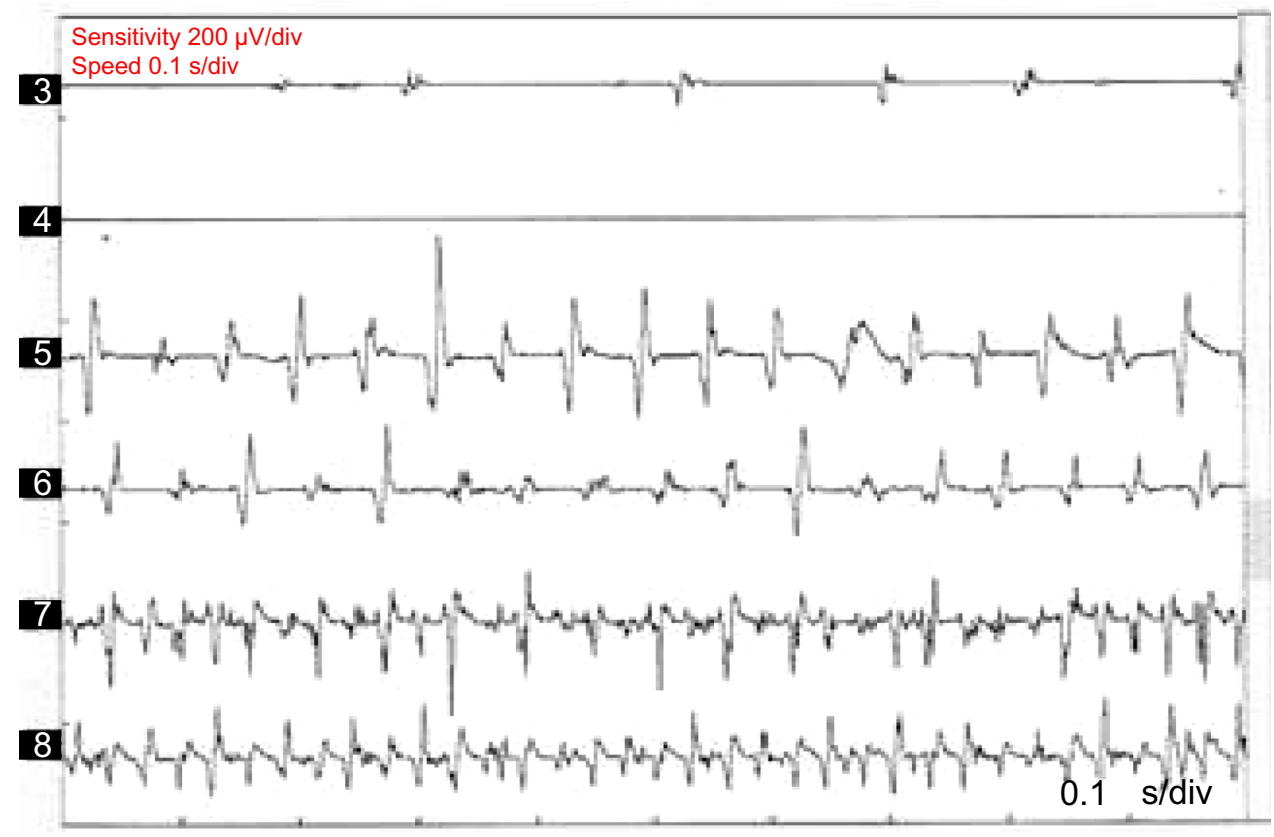

Figure I Polymyographic recordings in a patient with OT.

Notes: Polymyographic recordings: channels are right-sided biceps brachii, forearm flexor muscle, forearm extensor muscle, rectus femoris, anterior tibialis, and gastrocnemius, respectively. A $16 \mathrm{~Hz}$ tremor is seen over the rectus femoris, anterior tibialis, and gastrocnemius muscles during standing (sensitivity $200 \mu \mathrm{V} /$ div, $0 . \mathrm{I}$ ms/div). A very high frequency tremor also appears on the upper extremity.

Abbreviation: OT, orthostatic tremor.

Although a family history of Pure OT is rare, stronger family history of other movement disorders appears to be more common among patients with "OT Plus." The family history of PD, essential tremor, and other less specified tremor has been documented in first-degree relatives of patients with OT plus. In the series by McManis and Sharbrough, ${ }^{3} 24$ of the 30 subjects had a family history of movement disorder, and among those, only two had a family member with similar limb tremor even though these relatives were not evaluated by the authors. It is, however, unclear from the study whether the patients had Pure OT or OT Plus.

\section{Clinical profile}

In a retrospective review of 41 cases with a clinical diagnosis and electrophysiological diagnosis of OT seen over a 16-year period (1986-2001) at the National Hospital for Neurology and Neurosurgery, Gerschlager et al ${ }^{22}$ profiled the demographic characteristics of their cohort of patients with OT. Of the 41 cases, 28 had been reviewed in the preceding 3 years for a follow-up. Thirty-one (75\%) patients were classified as having primary OT. Of these, only seven had leg tremors while the other 24 had accompanying arm tremor. Lack of electrophysiological assessment of the arm tremor in this study limited the ability of the authors to characterize the tremor accurately (the presence of arm tremor among the cohort became apparent during the review). It is unclear whether the postural arm tremor in these OT patients is similar to ET, or whether OT leg tremor in these cases is part of ET, or whether the postural arm tremor is part of OT. Yaltho and $\mathrm{Ondo}^{21}$ reported that in a larger case series ( $\mathrm{n}=45), 40 / 45(89 \%)$ had primary OT with $(n=30)$ or without $(n=10)$ an associated postural arm tremor. In this series, 5/45 (11\%) had OT Plus. Of recent, in the

Table 2 Demography of patients with OT

\begin{tabular}{|c|c|c|c|c|c|c|c|}
\hline Authors & $\begin{array}{l}\text { Year of } \\
\text { study }\end{array}$ & $\begin{array}{l}\text { No of } \\
\text { cases }\end{array}$ & $\begin{array}{l}\text { Mean age } \\
\text { of onset } \\
\text { (years) }\end{array}$ & M:F & $\begin{array}{l}\text { OT Plus } \\
\text { (\%) }\end{array}$ & $\begin{array}{l}\text { Positive family } \\
\text { history (n [\%]) }\end{array}$ & $\begin{array}{l}\text { Mean period of } \\
\text { follow-up (years) }\end{array}$ \\
\hline McManis and Sharbrough ${ }^{3}$ & 1993 & 30 & 54 & $\mathrm{I}: 2$ & - & - & - \\
\hline Gerschlager et $\mathrm{al}^{22}$ & 2004 & 41 & 50.4 & $\mathrm{I}: 1.92$ & 25 & $5(13.9)^{*}$ & 3 \\
\hline Piboonurak et $\mathrm{al}^{20}$ & 2005 & 26 & 57.05 & $\mathrm{I}: 4.2$ & 15.4 & - & - \\
\hline Yaltho and Ondo ${ }^{21}$ & 2014 & 45 & 59.5 & $\mathrm{I}: 0.96$ & II & $3(7)$ & 4.5 \\
\hline Ganos et $\mathrm{al}^{5}$ & 2015 & 68 & 52.7 & $\mathrm{I}: 3.25$ & 13.2 & I (I.6) & 5 \\
\hline
\end{tabular}

Note: *Details of family history were available in 36 patients and only five had a positive family history of tremor.

Abbreviations: OT, orthostatic tremor; M, male; F, female. 
largest multicenter cohort of patients with OT, ${ }^{5}$ a clear female preponderance $(76.5 \%)$ was demonstrated just like most of the other studies. In this survey, $86.8 \%$ of patients presented with isolated OT and $13.2 \%$ had additional neurological features. Table 2 summarizes demographic and clinical characteristics from various studies.

While other neurological disorders can coexist with OT, in some patients, OT may precede other neurological disorders/ symptoms, sometimes for as long as 20 years as in the report of dementia with lewy bodies in OT patients by Yaltho and Ondo. ${ }^{21}$ In the series by Ganos et al, ${ }^{5}$ seven patients developed new neurological symptoms. One patient developed PD, and five others became slow with gait difficulties, raising the clinical suspicion of PD. However, normal dopamine transporter SPECT scans (DatSCANs) were found in four of them; raising the suspicion that slowness of gait/difficulties could be compensatory to the leg tremor and unsteadiness. ${ }^{5}$

\section{Pathophysiology}

The pathophysiological mechanism underlying the development and the manifestation of OT is yet to be fully understood. Available literature has implicated several neuronal circuitry in the cerebellum, brain stem, thalamostriate, and corticosubcortical pathways..$^{25,26}$ The cerebello-thalamocorticospinal loop, in particular, has been implicated. ${ }^{27}$ It is widely accepted, however, that a central oscillator located in the posterior fossa is responsible for the generation and, probably, the perpetration of OT. The ability to reset OT by electrical stimulation over the posterior fossa further buttresses this theory. ${ }^{28}$ It has also been suggested that the spinal cord may generate the $16 \mathrm{~Hz}$ tremor. ${ }^{29}$ Spinal cord dorsal column stimulation, typically used for the treatment of medically refractory pain, was beneficial in two patients with OT. Using a stimulation frequency of $50-150 \mathrm{~Hz}$, Krauss et $\mathrm{al}^{27}$ demonstrated both subjective and objective improvement in unsteadiness in patients with OT, suggesting that the spinal cord may be associated with the generation and/or modulation of the tremor. Gerschlager et $\mathrm{al}^{22}$ have proposed a "double lesion" model for the manifestation of OT. According to this model, it is hypothesized that an abnormally active oscillator would have the key role, but OT would only develop if coupled with additional dysfunction at the level of basal ganglia or the cerebellum, resulting in deficient control of the oscillator.

Neurophysiological evaluation of patients has thrown some light on the mechanism of OT generation. In a particular patient, the frequency and timing pattern of the $16 \mathrm{~Hz}$ burst of the tremor is the same and fixed, although this fluctuates when such individual assumes a different posture. The high-frequency EMG bursts are time locked and bilateral in arm, leg, truncal, and even facial muscles. ${ }^{26}$ It has been posited that the abnormally strong peripheral manifestation of the $16 \mathrm{~Hz}$ central nervous system oscillation merely unmasks normal central processes rather than a primary pathology of central oscillators the POT. Sharott et $\mathrm{al}^{30}$ postulated that the fast and synchronous tremor might be an exaggeration of physiological postural response under the condition of extreme imbalance since it was shown that a $16 \mathrm{~Hz}$ tremor can be recorded in healthy subjects when made extremely unstable either by galvanic vestibular stimulation or by leaning backward. ${ }^{26,30}$ Objective instability in OT has been confirmed using force platform recordings that demonstrated increased sway path in OT. However, body sway assessment under several conditions has shown a dissociation between objective measurement and subjective feelings of unsteadiness by the patients. ${ }^{31}$ The authors also suggested that the unsteadiness in OT is caused by a tremulous disruption of proprioceptive afferent activity from the legs causing a cocontraction of the leg muscles to increase stability. The resultant increase in tremor-locked muscles activity further blocks the proprioceptive input, creating a vicious cycle. However, these authors found that the tremor amplitude is independent of objective measures of unsteadiness. ${ }^{31}$

Although functional neuroimaging studies have yielded inconclusive evidence of nigrostriatal dopaminergic system involvement, reports of early improvement with dopaminergic agents in some OT patients and the association of OT with PD have suggested an involvement of the dopaminergic system. Katzenschlager et $\mathrm{al}^{32}$ have demonstrated a modest bilateral reduction in nigrostriatal dopamine transporter level using ${ }^{123}$ I-FP-CIT (2- $\beta$-carbomethoxy-3- $\beta$-(-4-iodophenyl)$N$-(3-fluoropropyl)-nortropane) single-photon emission computed tomography in a group of eleven OT patients. In that study, PD was thoroughly screened for (all the patients had normal olfaction on the University of Pennsylvania Smell Identification Test), and no other neurological syndrome was identified, indicating that the mild reduction in nigrostriatal dopaminergic transmission was not due to unidentified PD. In agreement with the previous findings, Spiegel et al ${ }^{33}$ equally demonstrated an echogenic substantia nigra in six OT patients using transcranial sonography.

In most other functional imaging studies conversely, dopaminergic imaging in patients with Pure OT has largely shown normal nigrostriatal dopamine transporter tracer levels. ${ }^{5,34-37}$ The absence of appreciable or sustained improvement with dopaminergic agents further supports this observation. 
Because of this tenuous and rather inconclusive association with the nigrostriatal dopaminergic system, Trocello et $\mathrm{al}^{35}$ have proposed a classification system with separation of highfrequency OT into three different subtypes. Type A corresponds to primary OT without dopaminergic loss; type B consists of OT with mild dopaminergic loss, but no parkinsonian symptoms; and type C consists of OT associated with PD. ${ }^{35}$ Cerebellar dysfunction (at least subclinically) has also been implicated in the pathophysiology of OT, ${ }^{27,36}$ and positron emission tomography studies have demonstrated increased blood flow to the cerebellum and the lentiform nuclei in patients with POT. ${ }^{37}$ Even though florid clinical signs of cerebellar abnormalities are rare, Feil et $\mathrm{al}^{38}$ have documented cerebellar signs such as upper limb dysmetria and intention tremor among a cohort of patients with POT in a recent study on long-term course of OT. ${ }^{38}$ Albeit, with the history of alcohol consumption in about a third of the cohort, alternative causes of the cerebellar dysfunctions, such as alcoholism, are suspected.

\section{Time course and progression}

The absence of a systematic study of the natural history of OT limits the knowledge about its course to available anecdotal reports. The course of OT is often slowly progressive. Although few studies have studied long-time follow-up of patients with OT, the study by Ganos et $\mathrm{al}^{5}$ followed up patients for at least 5 years and found that $\sim 80 \%$ of the cohort reported symptom worsening within the observed timeframe. In the study by Feil et al, ${ }^{38} 78 \%$ of the patients demonstrated worsening of symptoms. According to Ganos et al, ${ }^{5}$ patients with clinical worsening had longer disease duration than those without (median 15.5 years vs 10.5 years, respectively).
Because the high-frequency tremor that characterizes OT remains unchanged over time (even though amplitude may change), it appears that the observed worsening of body sways over time is not occasioned by the tremor. An alternative hypothesis is that with time, as well as aging, there is a possible alteration of adaptive postural responses with decreased ability to control and minimize center of mass motion. ${ }^{5}$

Furthermore, some patients may have a spatial spread of the tremor to the trunks and upper extremities as the disease progresses. Although upper limb postural tremor with lower frequency (mimicking ET) may be observed in OT ${ }^{39,40}$ (Figure 2), it has been suggested that this slow arm tremor could represent a subharmonic of the leg tremor that has higher frequencies. ${ }^{5}$ Also, in the course of the disease, patients with OT may proceed to develop other neurological conditions, especially PD and essential tremor. Other neurological disorders that have been documented in patients with OT include dementia with Lewy bodies, ataxic disorders, restless leg syndrome, orofacial dyskinesia, and periodic limb movement in sleep. ${ }^{4,521}$ Patients with OT have been found to have a markedly impaired quality of life as measured by the Medical Outcomes Study Short Form Health Survey (SF-36). ${ }^{41}$ Physical functioning, physical role limitations, social functioning, and emotional role limitations were the predominantly impaired domains of quality of life. Among this cohort, depressive symptomatology was also highly prevalent, and it ranges between moderate to severe depression. ${ }^{41}$

\section{Treatments}

Just like the other aspects of this enigmatic illness, there is no large clinical trial to test the efficacy of the commonly used

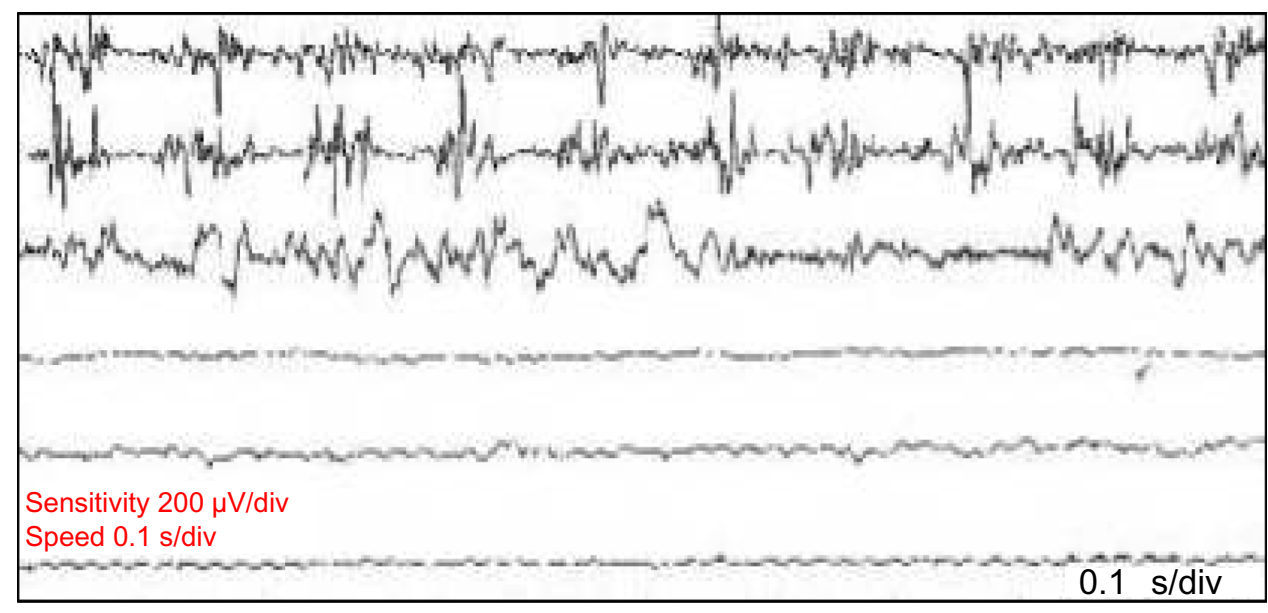

Figure 2 Postural tremor in a patient with OT.

Notes: A $10 \mathrm{~Hz}$ postural tremor of the upper extremity with no lower extremity tremor during sitting (sensitivity $200 \mu \mathrm{V} /$ div, $0.1 \mathrm{~ms} / \mathrm{div}$ ). Abbreviation: OT, orthostatic tremor. 
drugs such as clonazepam, gabapentin, primidone, valproate, phenobarbital, levodopa, and pramipexole. Treatment is difficult as the symptoms are often refractory to medication, and in some patients, the initial benefit is followed by loss of efficacy in the long term. ${ }^{4,22}$

\section{Clonazepam}

Clonazepam is usually recommended as first-line drug treatment probably based on the report of Heilman. ${ }^{2}$ Although it is arguably more beneficial than most other drugs, its side effects may be more. Some authors have recommended the use of gabapentin as the first line.$^{41}$ Control trial of clonazepam in OT is scarce in the literature.

\section{Gabapentin}

Gabapentin, a $\gamma$-aminobutyric acid analogue, has been found to be beneficial in patients with OT. Both open-label and cross-over trials have consistently demonstrated the benefit of gabapentin in reducing the tremor amplitude and/or severity, the length of the sway path, and the confidence area of the sway path compared to baseline. ${ }^{42-45}$

\section{Levodopa and dopamine agonist}

In patients with or at risk of parkinsonism, levodopa or dopamine agonist may be helpful. ${ }^{4}$ In a series by Wills et $\mathrm{al}^{46}$ in which eight patients were treated with levodopa, five patients experienced benefits. One patient had classical OT and developed PD 9 years after its onset. Levodopa improved both parkinsonian symptoms and the high-frequency tremor. Another patient had sustained benefit to levodopa and then developed PD. However, only one patient, out of the eight treated with levodopa, ${ }^{46}$ had a benefit sustained $>24$ months. ${ }^{22}$ An open-label study of levodopa treatment $>2$ months using $600 \mathrm{mg} / \mathrm{d}$ led to some improvement in two of five patients but no significant overall change and no sustained benefit. ${ }^{32}$ Pramipexole, a dopamine agonist, was effective in a single case report. ${ }^{47}$ Summarily, dopaminergic agents may be helpful in some patients over a short period of time, particularly those with, or at risk of developing PD.

The trial of levetiracetam in a double-blind placebocontrolled cross-over study showed a disappointing result. ${ }^{47}$ Primidone, however, was reported to be beneficial in a patient $^{48}$ but no available clinical trials yet.

\section{Botulinum toxin}

Although it has been suggested that jaw tremor in the frequency of OT may be treated successfully with botox, ${ }^{49}$ a trial of $200 \mathrm{IU}$ of abobotulinumtoxin A was found to be ineffective in the treatment of OT. Eight patients with electrophysiologically confirmed POT were evaluated in this randomized, doubleblind, and placebo-controlled cross-over design study. Each patient received injections of either $200 \mathrm{mU}$ abobotulinumtoxin A or $0.9 \%$ saline in the tibialis anterior bilaterally and then crossed over after 20 weeks. There were no significant differences in the primary outcome measures of time from standing to unsteadiness or symptom diary scores. ${ }^{49}$

Table 3 Drug studies in orthostatic tremor

\begin{tabular}{|c|c|c|c|c|}
\hline Agent & $\begin{array}{l}\text { Year and } \\
\text { reference }\end{array}$ & Design & Outcome & Comments \\
\hline \multirow[t]{4}{*}{ Gabapentin } & $1998^{42}$ & Seven cases, open label & $\begin{array}{l}\text { Subjective benefit in tremor severity, latency to } \\
\text { onset, or both }\end{array}$ & $\begin{array}{l}\text { Effective dose } \\
300-1,800 \mathrm{mg} / \mathrm{d}\end{array}$ \\
\hline & $1998^{43}$ & $\begin{array}{l}\text { Four cases, double-blind } \\
\text { crossover study }\end{array}$ & $\begin{array}{l}\text { Subjective benefit and improvement in a tremor } \\
\text { rating scale }\end{array}$ & $\begin{array}{l}\text { Effective dose } \\
300-2,400 \mathrm{mg} / \mathrm{d}\end{array}$ \\
\hline & $2005^{44}$ & Six cases, open label & Effective in improving tremor, stability, and QOL & $\begin{array}{l}300 \mathrm{mg} \text { thrice daily } \\
\text { was used }\end{array}$ \\
\hline & $2006^{45}$ & $\begin{array}{l}\text { Six cases, double-blind } \\
\text { crossover study }\end{array}$ & $\begin{array}{l}\text { Effective in reducing the tremor amplitude, the } \\
\text { length of the sway path, and the confidence area } \\
\text { of the sway path compared to baseline }\end{array}$ & $\begin{array}{l}\text { Effective dose } \\
600-2,700 \mathrm{mg} / \mathrm{d}\end{array}$ \\
\hline Levetiracetam & $2011^{47}$ & $\begin{array}{l}12 \text { cases, double-blind } \\
\text { crossover study }\end{array}$ & $\begin{array}{l}\text { No effect on stance duration, total track length } \\
\text { of the sway path, and tremor total power }\end{array}$ & $\begin{array}{l}\text { Mild-to-moderate } \\
\text { dizziness, fatigue, } \\
\text { and nausea }\end{array}$ \\
\hline $\begin{array}{l}\text { Abobotulinum- } \\
\text { toxin A }\end{array}$ & $2013^{49}$ & $\begin{array}{l}\text { Eight cases, randomized, } \\
\text { double-blind, and placebo- } \\
\text { controlled cross-over } \\
\text { design study }\end{array}$ & $\begin{array}{l}\text { No effects on time from standing to } \\
\text { unsteadiness or symptom diary scores }\end{array}$ & $\begin{array}{l}\text { Frequent postural } \\
\text { instability and falls }\end{array}$ \\
\hline Levodopa & $2003^{46}$ & $\begin{array}{l}\text { An open-label study with } \\
\text { levodopa treatment over } \\
2 \text { months }\end{array}$ & $\begin{array}{l}\text { Some improvement in two of five subjects. } \\
\text { No significant overall change and no sustained } \\
\text { benefit }\end{array}$ & $\begin{array}{l}\text { Effective dose } \\
600 \mathrm{mg} / \mathrm{d}\end{array}$ \\
\hline
\end{tabular}

Abbreviation: QOL, quality of life. 
Drug treatment in OT is largely inadequate. Only $\sim 12 \%$ of patients who did not respond to clonazepam and gabapentin would find other medications beneficial. ${ }^{22}$

\section{Surgical treatment}

Surgical intervention has been tried in a few patients with severe, medication-resistant OT., ${ }^{5,22}$ Bilateral deep brain stimulation (DBS) of the thalamic nucleus ventralis intermedius medialis (Vim) appears to produce sustained clinical improvement. ${ }^{50-52}$ However, clinical improvement was not sustained in a patient with unilateral thalamic Vim DBS. ${ }^{53}$ Spinal cord dorsal column stimulation has been beneficial in two patients with OT. ${ }^{27}$ Thalamic DBS can be complicated by electrode displacement with resultant loss of function and worsening of tremor as in the report by Contarino et al. ${ }^{54}$

The therapeutic studies that have been undertaken since 1998 are summarized in Table 3. In the future, effective therapies are more likely to stem from a better understanding of the fundamental pathophysiology of OT. Larger clinical trials are needed to influence the therapeutic decisions. Although the disease is slowly progressive, development of disease-modifying treatment may be the next quest, especially in view of its association with other neurodegenerative diseases, such as PD.

\section{Conclusion}

Despite greater awareness in the recent times since its first report, OT still remains enigmatic. Increasing knowledge about its pathophysiology has been assisted by the results of functional neuroimaging and successful therapies such as spinal cord stimulation and thalamic DBS. Because of its rarity, large cohort studies may be a herculean task. The need for such large-scale study is however pressing, if we are to get a better understanding of this disease. Novel therapies are also required in view of the insignificant and inconsistent benefits of the currently available therapeutic options.

\section{Acknowledgements}

The author thanks Drs Rufus O Akinyemi and Aysegul Gunduz for their helpful comments on the manuscript and also thanks Professor Meral E Kiziltan, who supplied the figures used in this review.

\section{Disclosure}

The author reports no conflicts of interest in this work.

\section{References}

1. Pazzaglia P, Sabattini L, Lugaresi E. Su di un singolare disturbodeura stazione eretta (osservazione di tri casi) [About a singular disturbance of upright position (observation of three cases)]. Riv Freniatr. 1970;96: 450-457. Italian.
2. Heilman KM. Orthostatic tremor. Arch Neurol. 1984;41(8):880-881.

3. McManis PG, Sharbrough FW. Orthostatic tremor: clinical and electrophysiological characteristics. Muscle Nerve. 1993;16:1254-1260.

4. Gerschlager W, Brown P. Orthostatic Tremor - a review. Handb Clin Neurol. 2011;100:457-462.

5. Ganos C, Maugest L, Apartis E, et al. The long-term outcome of orthostatic tremor. J Neurol Neurosurg Psychiatry. 2016;87(2):167-172.

6. Walker FO, McCormick GM, Hunt VP. Isometric features of orthostatic tremor: an electromyographic analysis. Muscle Nerve. 1990;13:918-922.

7. Veilleux M, Sharbrough FW, Kelly JJ, Westmoreland BF, Daube JR. Shaky-legs syndrome. J Clin Neurophys. 1987;4:304-305.

8. Boroojerdi B, Ferbert A, Foltys H, Kosinski CM, Noth J, Schwarz M. Evidence for a non-orthostatic origin of orthostatic tremor. $J$ Neurol Neurosurg Psychiatry. 1990;66:284-288.

9. Brown P. New clinical sign for orthostatic tremor. Lancet. 1995;346: 306-307.

10. Britton TC, Thompson PD, van der Kamp W, et al. Primary orthostatic tremor: further observations in six cases. $J$ Neurol. 1992;239(4):209-217.

11. Deuschl G, Bain P, Brin M. Consensus statement of the Movement Disorder Society on Tremor. Ad Hoc Scientific Committee. Mov Disord. 1998;13(suppl 3):2-23.

12. Adebayo PB, Gunduz A, Kiziltan ME, Kiziltan G. Upper limbs spread of orthostatic tremor following hip replacement surgery. Neurol India. 2014;62(4):462-463.

13. Uncini A, Onofri M, Basciani M, Cutarella R, Gambi D. Orthostatic tremor: report of two cases and an electrophysiological study. Mov Disord. 1989;79(2):119-122.

14. Leu-Semenescu S, Roze E, Vidailhet M, et al. Myoclonus or tremor in orthostatism: an under-recognized cause of unsteadiness in Parkinson's disease. Mov Disord. 2007;22:2063-2069.

15. Rigby HB, Rigby MH, Caviness JN. Orthostatic tremor: a spectrum of fast and slow frequencies or distinct entities? Tremor Other Hyperkinet Mov (NY). 2015;5:324.

16. Williams ER, Jones RE, Baker SN, Baker MR. Slow orthostatic tremor can persist when walking backward. Mov Disord. 2010;25:795-797.

17. Baker M, Fisher K, Lai M, Duddy M, Baker S. Slow orthostatic tremor in multiple sclerosis. Mov Disord. 2009;24:1550-1553.

18. Kim JS, Lee MC. Leg tremor mimicking orthostatic tremor as an initial manifestation of Parkinson's disease. Mov Disord. 1993;8: 397-398.

19. Coffeng SM, Hoff JI, Tromp SC. A slow orthostatic tremor of primary origin. Tremor Other Hyperkinet Mov (N Y). 2013;3:1-3.

20. Piboolnurak P, Yu QP, Pullman SL. Clinical and neurophysiologic spectrum of orthostatic tremor: case series of 26 subjects. Mov Disord. 2005;20(11):1455-1461.

21. Yaltho TC, Ondo WG. Orthostatic tremor: a review of 45 cases. Parkinsonism Relat Disord. 2014;20(7):723-725.

22. Gerschlager W, Münchau A, Katzenschlager R, et al. Natural history and syndromic associations of orthostatic tremor: a review of 41 patients. Mov Disord. 2004;19(7):788-795.

23. Contarino MF, Welter ML, Agid Y, Hartmann A. Orthostatic tremor in monozygotic twins. Neurology. 2006;66:1600-1601.

24. Bhattacharyya KB, Das D. Familial orthostatic tremor, and essential tremor in two young brothers: a rare entity. Ann Indian Acad Neurol. 2013;16(2):276-278.

25. Setta F, Manto MU. Orthostatic tremor associated with a pontine lesion or cerebellar disease. Neurology. 1998;51:923.

26. McAuley JH, Britton TC, Rothwell JC, Findley LJ, Marsden CD. The timing of primary orthostatic tremor bursts has a task-specific plasticity. Brain. 2000;123:254-266.

27. Krauss JK, Weigel R, Blahak C, et al. Chronic spinal cord stimulation in medically intractable orthostatic tremor. J Neurol Neurosurg Psychiatry. 2006;77:1013-1016.

28. Wu YR, Ashby P, Lang AE. Orthostatic tremor arises from an oscillator in the posterior fossa. Mov Disord. 2001;16:272-279. 
29. Norton JA, Wood DE, Day BL. Is the spinal cord the generator of $16-\mathrm{Hz}$ orthostatic tremor? Neurology. 2004;62:632-634.

30. Sharott A, Marsden J, Brown P. Primary orthostatic tremor is an exaggeration of a physiological response to instability. Mov Disord. 2003;18:195-199.

31. Fung VS, Sauner D, Day BL. A dissociation between subjective and objective unsteadiness in primary orthostatic tremor. Brain. 2001;124:322-330.

32. Katzenschlager R, Costa D, Gerschlager W, et al. [123I]-FP-CIT-SPECT demonstrates dopaminergic deficit in orthostatic tremor. Ann Neurol. 2003;53:489-496.

33. Spiegel J, Behnke S, Fuss G, Becker G, Dillmann U. Echogenic substantia nigra in patients with orthostatic tremor. J Neural Transm. 2005;112:915-920.

34. Wegner F, Strecker K, Boeckler D, et al. Intact serotonergic and dopaminergic systems in two cases of orthostatic tremor. $J$ Neurol. 2008;255:1840-1842.

35. Trocello JM, Zanotti-Fregonara P, Roze E, et al. Dopaminergic deficit is not the rule in orthostatic tremor. Mov Disord. 2008;23:1733-1738.

36. Setta F, Jacquy J, Hildebrand J, Manto MU. Orthostatic tremor associated with cerebellar ataxia. J Neurol. 1998;245:299-302.

37. Wills AJ, Thompson PD, Findley LJ, Brooks DJ. A positron emission tomography study of primary orthostatic tremor. Neurology. 1996; 46:747-752.

38. Feil K, Böttcher N, Guri F, et al. Long-term course of orthostatic tremor in serial posturographic measurement. Parkinsonism Relat Disord. 2015;21(8):905-910.

39. Raudino F, Muscia F, Osio M. Orthostatic tremor and I123-FP-CITSPECT: report of a case. Neurol Sci. 2009;30:365-366.

40. FitzGerald PM, Jankovic J. Orthostatic tremor: an association with essential tremor. Mov Disord. 1991;6:60-64.

41. Gerschlager W, Katzenschlager R, Schrag A, et al. Quality of life in patients with orthostatic tremor. J Neurol. 2003;250(20):212-215.

42. Evidente VG, Adler CH, Caviness JN, Gwinn KA. Effective treatment of orthostatic tremor with gabapentin. Mov Disord. 1998;13: 829-831.
43. Onofrij M, Thomas A, Paci C, D'Andreamatteo G. Gabapentin in orthostatic tremor: results of a double-blind crossover with placebo in four patients. Neurology. 1998;51:880-882.

44. Rodrigues JP, Edwards DJ, Walters SE, et al. Gabapentin can improve postural stability and quality of life in primary orthostatic tremor. Mov Disord. 2005;20:865-870.

45. Rodrigues JP, Edwards DJ, Walters SE, et al. Blinded placebo crossover study of gabapentin in primary orthostatic tremor. Mov Disord. 2006;21(7):900-905.

46. Wills AJ, Brusa L, Wang HC, Brown P, Marsden CD. Levodopa may improve orthostatic tremor: case report and trial of treatment. J Neurol Neurosurg Psychiatry. 1999;66:681-684.

47. Hellriegel H, Raethjen J, Deuschl G, Volkmann J. Levetiracetam in primary orthostatic tremor: a double-blind placebo-controlled crossover study. Mov Disord. 2011;26(13):2431-2434.

48. Finkel MF. Pramipexole is a possible effective treatment for primary orthostatic tremor (shaky leg syndrome). Arch Neurol. 2000;57: 1519-1520.

49. Bertram K, Sirisena D, Cowey M, Hill A, Williams DR. Safety and efficacy of botulinum toxin in primary orthostatic tremor. J Clin Neurosci. 2013;20(11):1503-1505.

50. Gonzalez-Alegre P, Kelkar P, Rodnitzky RL. Isolated high-frequency jaw tremor relieved by botulinum toxin injections. Mov Disord. 2006;21(7):1049-1050.

51. Yaltho TC, Ondo WG. Thalamic deep brain stimulation for orthostatic tremor. Tremor Other Hyperkinet Mov (N Y). 2011;1.

52. Guridi J, Rodriguez-Oroz MC, Arbizu J, et al. Successful thalamic deep brain stimulation for orthostatic tremor. Mov Disord. 2008; 23(13):1808-1811.

53. Espay AJ, Duker AP, Chen R, et al. Deep brain stimulation of the ventral intermediate nucleus of the thalamus in medically refractory orthostatic tremor: preliminary observations. Mov Disord. 2008;23(16):2357-2362.

54. Contarino MF, Bour LJ, Schuurman PR, et al. Thalamic deep brain stimulation for orthostatic tremor: clinical and neurophysiological correlates. Parkinsonism Relat Disord. 2015;21(8):1005-1007.
Degenerative Neurological and Neuromuscular Disease

\section{Publish your work in this journal}

Degenerative Neurological and Neuromuscular Disease is an international, peer-reviewed, open access journal focusing on research into degenerative neurological and neuromuscular disease, identification of therapeutic targets and the optimal use of preventative and integrated treatment interventions to achieve improved outcomes, enhanced

\section{Dovepress}

survival and quality of life for the patient. The manuscript management system is completely online and includes a very quick and fair peer-review system. Visit http://www.dovepress.com/testimonials.php to read real quotes from published authors. 